\title{
Intraocular lens power calculations in the triple procedure
}

\author{
AMR SALAH-EDDIN ABDEL-HAKIM AND AHMAD KHALIL \\ From the Department of Ophthalmology, Cairo University Hospital, Cairo, Egypt
}

SUMmARY When a triple procedure is planned, calculation of the intraocular lens becomes a problem. Postoperative corneal power bears no relation to preoperative power, and the axial length of the globe also changes. A prospective study of 24 keratoplasties revealed a close relationship between postoperative corneal power and donor corneal power. Changes in axial length were found to be too small to produce errors in calculation. The equation derived in this series to describe the relation between postoperative and donor corneal power is applicable only when certain trephine sizes are used and when the recepient cornea is not excessively scarred.

When a corneal opacity and cataract coexist, the triple procedure-namely, keratoplasty, cataract extraction, and intraocular lens implantationbecomes one of the options a surgeon has to consider. Its main advantage is more rapid visual rehabilitation than that resulting from multiple-step treatment. Proper calculation of lens power depends on the accurate measurement of corneal power $(\mathrm{K})$ and axial length (L) preoperatively. ${ }^{1}$ In the triple procedure the postoperative changes in $\mathrm{K}$ and $\mathrm{L}$ induced by keratoplasty may be a major source of error in lens power selection. Some surgeons use the preoperative $\mathrm{K}$ of the operated or fellow eye in their formulae. ${ }^{2}$ Others use average $\mathrm{K}$ values derived from their own series $^{3}$ on the assumption that there is no correlation between pre- and postoperative $\mathrm{K}$ values.

In this prospective study readings obtained from 24 keratoplasties are analysed. The trephine diameters were the same at each operation. A $7.5 \mathrm{~mm}$ trephine was used to obtained the donor button and a $7 \mathrm{~mm}$ trephine to cut the recepient bed. The same surgical technique was followed by a single surgeon in all 24 cases. Pre- and postoperative $\mathrm{K}$ and $\mathrm{L}$ readings were recorded as well as 'donor $\mathrm{K}$ '. A mathematical model has been constructed to explain the relation between

Correspondence to Dr Amr Salah-Eddin Abdel-Hakim, PO Box 714, Maadi, 11431 Cairo, Egypt. donor $\mathrm{K}$ and final postoperative $\mathrm{K}$. Another model was set up to calculate changes in L after surgery.

\section{Material and methods}

Twenty-four eyes with weak vision due to corneal opacification were selected. Table 1 shows the pathology in them. Eight patients were female and 16 male. Their ages ranged from 16 to 52 years.

\section{PREOPERATIVE MEASUREMENTS}

The recepient eye. (a) Corneal power was measured with the Haag-Streit model keratometer. In case of astigmatism, the average $\mathrm{K}$ was recorded. (b) Ultrasonic axial length (L) was measured in $\mathrm{mm}$ with the Cooper vision imaging machine. $\mathrm{L}$ was measured in seven cases only.

The donor globe. $\mathrm{K}$ in the donor globe was measured as follows. Fresh donor globes were obtained within six hours of death. Under strict sterile conditions Ringer-lactate solution was injected into the vitreous chamber with a $25 \mathrm{G}$ needle introduced 10 to $12 \mathrm{~mm}$ behind the limbus obliquely through the sclera and pointing towards the centre of the globe. Enough solution was injected until the globe was felt to become firm. The needle was then removed and the globe pressure was checked by an applanation tonometer. The globe was held by one of 
Table 1 The corneal pathological states in the recipient eyes

\begin{tabular}{lcc}
\hline Pathology & No. of eyes & Percentage \\
\hline Leucoma & 12 & 50 \\
Keratoconus & 4 & $16 \cdot 7$ \\
Dystrophy & 4 & $16 \cdot 7$ \\
Blood staining & 2 & $8 \cdot 3$ \\
Endothelial decompensation & 2 & $8 \cdot 3$ \\
\hline
\end{tabular}

the rectus stumps in front of a Goldmann tonometer. Counter support was applied lightly to the back of the globe by an assistant during measurement. In all globes the pressure was built up to about 15-20 $\mathrm{mm} \mathrm{Hg}$. The globe was then held in front of the keratometer and $\mathrm{K}$ was measured. The adjacent rectus stump was then held, the globe rotated through $90^{\circ}$, and a perpendicular $\mathrm{K}$ measured. The donor $\mathrm{K}$ is the average value of these two readings.

OPERATION

The donor button was obtained by a $7.5 \mathrm{~mm}$ trephine while the recepient bed was prepared by a $7 \mathrm{~mm}$ trephine. The graft was fixed by eight interrupted 10-0 nylon sutures together with a running continuous 10-0 nylon suture. Interrupted sutures were removed fourto six months after surgery, the running sutures after $12-18$ months.

POSTOPERATIVE MEASUREMENTS

Corneal power. (a) Early $\mathrm{K}$ readings were taken two days after surgery. (b) Serial K readings were recorded at monthly intervals up to nine months in all cases.

The axial length was measured in seven of the cases six to eight months postoperatively, when $\mathrm{K}$ was found to have become stable.

\section{Results}

Fig. 1 shows the distribution of preoperative recepient $\mathrm{K}$ measurement, the donor $\mathrm{K}$ as well as the early postoperative (two days) and final postoperative (nine months) $\mathrm{K}$ values.

Table 2 gives the average values of $K$ (with SD) in each of the above groups. The preoperative $\mathrm{K}$ ranged between 32.5 dioptres (D) and $59 \mathrm{D}$, average 44.82 $(7 \cdot 72) \mathrm{D}$. The high SD reflects the heterogeneity of this group of readings. Donor Ks were more uniform, lying between 40.5 and $45 \mathrm{D}$, average $42.39(1.41) \mathrm{D}$. Similarly early postoperative Ks were uniform. The average $\mathrm{K}$ was $50.53(1.47) \mathrm{D}$, lying between 48 and $53 \mathrm{D}$.

Monthly K measurements showed variations up to six to eight months postoperatively, after which readings became stable. At nine months post-

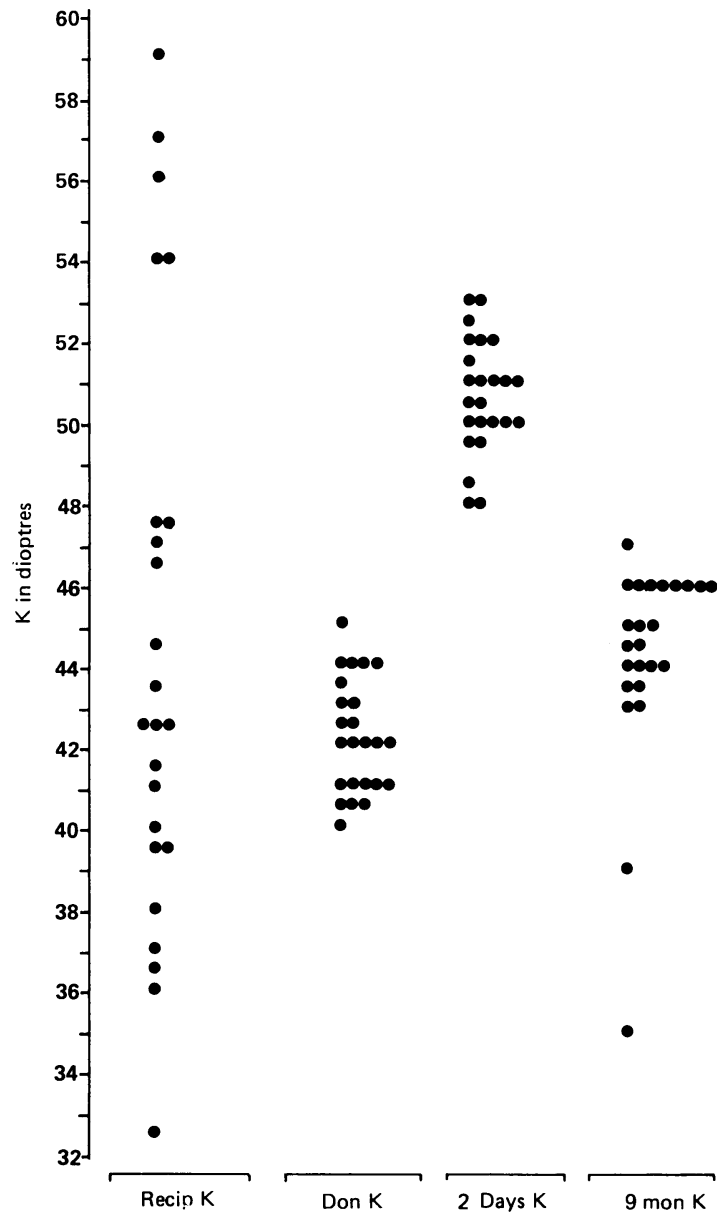

Fig. 1 The distribution of corneal power $K$ in 24 eyes. Recep $K=$ recepient preoperative $K$. Don $K=$ donor globe $K$. 2 Days $K=2$ days postoperative $K .9$ mon $K=9$ months postoperative $K$.

operatively the $K$ readings had an average of 44.05 (2.75) D, range 35 to $47 \mathrm{D}$. Two particular cases with heavy corneal scarring and vascularisation showed an abnormally excessive postoperative corneal flattening. If these two cases are omitted, the nine months postoperative K average becomes $44 \cdot 88(1 \cdot 23) \mathrm{D}$.

Table 3 gives preoperative recipient $K$ and $L$ values as well as postoperative $K$ and $L$ values in seven of the cases in this series. It also includes the actual changes in $\mathrm{L}$ together with the expected, mathematically calculated changes. Both the actual measurements and the mathematical calculations revealed minute negligible changes in L. Consequently the pre- and postoperative evaluation of $\mathrm{L}$ was omitted after the seventh case. 
Table 2 Average values of $K$ (with standard deviations) by groups

\begin{tabular}{lll}
\hline Group & Average $K$ & Range \\
\hline Recip preop & $44 \cdot 82(7 \cdot 72)$ & $32 \cdot 5-59$ \\
Donor & $42 \cdot 39(1 \cdot 41)$ & $40 \cdot 5-45$ \\
Postop 2 days & $50 \cdot 53(1 \cdot 47)$ & $48-53$ \\
Postop 9 months & $44.05(2 \cdot 75)$ & $35-47$ \\
Postop 9 months after omitting 2 cases & $44.88(1 \cdot 23)$ & $43-47$ \\
\hline
\end{tabular}

Recip preop $=$ corneal power of recepient eyes.

Donor $=$ corneal power of donor recipient eyes.

Postop 2 days $=$ corneal power 2 days after surgery.

Postop 9 months =corneal power 9 months after surgery.

Postop 9 months after omitting 2 cases=above group after omitting 2 cases that showed abnormally excessive corneal scarring.

Average $\mathrm{K}=$ mean value of corneal power in dioptres.

Range $=$ range of $K$ in the group.

\section{Discussion}

Troutman calculated a $0.67 \mathrm{D}$ increase in $\mathrm{K}$ for every $0.1 \mathrm{~mm}$ increase of donor button size over recipient bed size. ${ }^{4}$ Casey states that $0.5 \mathrm{~mm}$ discrepancy between donor and recipient may reduce hypermetropia by 'a dioptre or two'. ${ }^{5}$ Olson on the other hand reports a statistically insignificant difference between the refraction after same-size grafts and over-size grafts. ${ }^{6}$ This controversy stems from a basic error, which is the attempt to relate preoperative to postoperative corneal powers. As Kozansky and Cavanagh judiciously state, 'there is no relation between the preoperative and postoperative corneal powers'. ' The true relation is between the donor $\mathrm{K}$ and the postoperative recepient $\mathrm{K}$. After all, it is the donor corneal button that becomes 'squeezed' into a smaller bed with a consequent change in its curvature ( $\mathrm{K}$ becomes greater).

In Fig. 1 it is obvious how disparate the preoperative $\mathrm{K}$ values are. In addition to the different

Table 3 Preoperative and postoperative $K$ and $L$ values

\begin{tabular}{|c|c|c|c|c|c|}
\hline K preop & K 9mon & $L$ prop & L9mon & Real diff & Math diff \\
\hline $32 \cdot 5$ & 35 & $19 \cdot 7$ & 19.9 & 0.2 & 0.16 \\
\hline $46 \cdot 5$ & 44 & $24 \cdot 05$ & 23.9 & $-0 \cdot 15$ & -0.04 \\
\hline $36 \cdot 5$ & $39 \cdot 5$ & $23 \cdot 36$ & $23 \cdot 68$ & 0.32 & 0.06 \\
\hline 42 & 46 & $23 \cdot 87$ & 24 & $0 \cdot 13$ & 0.09 \\
\hline 43 & 47 & $22 \cdot 6$ & $22 \cdot 7$ & $0 \cdot 10$ & 0.06 \\
\hline 38 & 45 & 22.90 & $23 \cdot 2$ & $0 \cdot 30$ & $0 \cdot 14$ \\
\hline 54 & 39 & $24 \cdot 35$ & $23 \cdot 87$ & -0.48 & $-0 \cdot 165$ \\
\hline
\end{tabular}

$\mathrm{K}$ preop=preoperative corneal power in dioptres.

$\mathrm{K} 9 \mathrm{mon}=$ postoperative corneal power after 9 months.

$\mathbf{L}$ preop=preoperative axial length in $\mathrm{mm}$.

$\mathrm{L} 9 \mathrm{mon}=$ postoperative axial length after 9 months.

Real diff $=$ measured difference between $\mathrm{L} 9$ months and $\mathrm{L}$ preop.

Math diff $=$ mathematically calculated difference. pathological states involved, this disparity reflects the inaccuracy and difficulty in measuring $\mathrm{K}$ in scarred corneas with an irregular surface. Meanwhile donor $\mathrm{K}$ values are far more uniform. This is to be expected, since donors are selected on the basis of their "normal corneas'. Early postoperative $\mathrm{K}$ values are similarly rather uniform, though their average value is clearly higher than that of the donors. Nine months later this average value declines considerably, yet uniformity is still preserved.

The first two cases in the study demonstrate this fact clearly. One was a case of keratoconus with an average preoperative $\mathrm{K}$ of $57 \mathrm{D}$, while the other was a case of adherent scar with a $\mathrm{K}$ of $36 \cdot 5 \mathrm{D}$. Both at the same operative session received grafts from a single donor whose $\mathrm{K}$ was $\mathbf{4 0 . 5}$ in both eyes. Their two-day postoperative Ks were remarkably close (48.5 and 49.5 D respectively). A follow-up of corneal powers postoperatively showed a gradual decline for six to eight months before they became stable. Final K values measured nine months after surgery had an average of $44.05(2.75) \mathrm{D}$. This matches well with the average postoperative corneal powers reported by several other investigators. ${ }^{238}$

\section{Mathematical model}

In Fig. 2, if an arc whose length is a, with radius of curvature $\mathrm{r} 1$ and suspended on a chord $\mathrm{c} 1$, is transferred to another shorter chord $\mathrm{c} 2$ (with $\mathrm{c} 1>\mathrm{c} 2$ ), then the curvature of the arc a will become steeper, on the assumption of a new radius $\mathrm{r} 2$ where $\mathrm{r} 1>\mathrm{r} 2$ :

$$
r 1 \sin ^{-1}\left(\frac{c 1}{2 r 1}\right)=a=r 2 \sin ^{-1}\left(\frac{c 2}{2 r 2}\right),
$$

Where a represents the length of arc of the donor button. Its length depends on:

(1) $\mathrm{c} 1$, the length of the chord, or in other words the diameter of the trephine used to obtain this button $(7.5 \mathrm{~mm})$;

(2) $\mathrm{r} 1$ the radius of curvature of the donor cornea ( $\mathrm{K}$ value of the donor cornea).

This same button is applied to the recepient bed, prepared by a $7 \mathrm{~mm}$ trephine - that is, $\mathrm{c} 2$ becomes $7 \mathrm{~mm}$. It will attain a steeper curvature $\mathrm{r} 2$. This $\mathrm{r} 2$, which is the radius of curvature of graft postoperatively, depends on: (1) donor corneal curvature $\mathrm{r} 1$; (2) diameter of donor trephine $\mathrm{c} 1(7.5 \mathrm{~mm})$; and (3) diameter of recepient rephine $\mathrm{c} 2(7 \mathrm{~mm})$.

\section{GRAFT AND RECEPIENT BED RETRACTION}

When a donor button of $K=42.5 \mathrm{D}(\mathrm{r}=7.9 \mathrm{~mm})$, obtained by a $7.5 \mathrm{~mm}$ trephine is fixed into a recipient bed prepared by a $7 \mathrm{~mm}$ trephine, the mathematically expected postoperative $r$ would be $r=4.88$-that is, $\mathrm{K}>60 \mathrm{D}$. In practice this did not happen. The two- 
Fig. 2 The radius of curvature $\mathrm{r} 1$ of the arc a suspended on a chord $\mathrm{cl}$ changes to $\mathrm{r} 2$ if the length of the chord changes to $\mathrm{c} 2$, if $\mathrm{c} 2<\mathrm{c} 1$, then $\mathrm{r} 2<\mathrm{r} 1$ when a is constant.
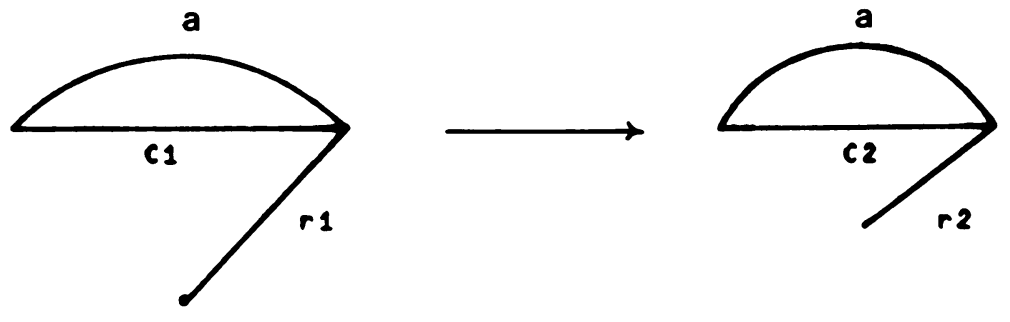

day postoperative $K$ was found to be $K=50 \cdot 5 \mathrm{D}$. This means that either the recipient bed expanded from $7 \mathrm{~mm}$ to $7.36 \mathrm{~mm}$ or that the length of arc of the button shrank from $7.81 \mathrm{~mm}$ to $7.3 \mathrm{~mm}$. It seems, however, that the bed and button change in size to some extent owing to the retraction of the collagenous corneal stroma when cut. Further changes occurred in graft size and bed width during the first six to eight months following surgery. The corneal power declined gradually to reach a steady state - 'final corneal power' - thereafter.

\section{EXCESSIVE CORNEAL SCARRING}

In corneas with heavy scarring the postoperative flattening was noticed to be excessive. Two cases in this series suffered in this way: the postoperative $\mathrm{K}$ dropped from $50 \mathrm{D}$ and $52.75 \mathrm{D}$, two days after surgery, to $35 \mathrm{D}$ and $39 \mathrm{D}$ after nine months. Measurement of the graft-bed interface at nine months showed an increase from $7 \mathrm{~mm}$ to 7.6 and $7.8 \mathrm{~mm}$ respectively. The recipient bed in scarred corneas seems to be liable to abnormal degrees of shrinkage, leading to unexpectedly low final $\mathrm{K}$ values.

\section{RELATION BETWEEN 'DONOR K' AND 'FINAL POSTOPERATIVE K'}

After omission of the two cases with excessive corneal scarring the average final postoperative $K$ becomes $44 \cdot 88$. That is to say:

When a $7.5 \mathrm{~mm}$ corneal button obtained from a donor globe with a corneal power $\mathrm{K} 1$ is applied to a receipient bed of $7 \mathrm{~mm}$ diameter, the expected final postoperative corneal power after nine months can be predicted from the equation:

$$
\mathrm{K} 2=\mathrm{K} 1+6 \% \mathrm{~K} 1 \text {. }
$$

\section{AXIAL LENGTH CHANGES}

Theoretically, any change in corneal curvature is expected to result in an associated change in axial length ${ }^{*} \mathrm{~L}$ where:

$$
{ }^{*} \mathrm{~L}=\left(2 \mathrm{r}_{2}-\sqrt{\left.4 \mathrm{r}_{2}^{2}-\mathrm{c}_{2}^{2}\right)}-\left(2 \mathrm{r}_{1}-\sqrt{4 \mathrm{r}_{1}^{2}-\mathrm{c}_{1}^{2}}\right)\right.
$$

In seven cases ${ }^{*} \mathrm{~L}$ was actually measured and mathematically calculated as well. In all seven cases ${ }^{*} \mathrm{~L}$, both by measurement and by calculation, proved to be negligibly small (Table 3 ). The preoperative axial length can safely be applied in the IOL calculations formula.

\section{CONCLUSION}

In calculating the IOL power $\mathrm{P}$ in eyes with an axial length between $22 \mathrm{~mm}$ and $24 \mathrm{~mm}$ the most commonly accepted formula is the SRK linear regression formula. ${ }^{9}$

$$
\mathrm{P}=\mathrm{A}-2 \cdot 5 \mathrm{~L}-0.9 \mathrm{~K} \text {, }
$$

where $\mathrm{A}$ is the lens constant specific to the type of lens.

If the axial length is $<22 \mathrm{~mm}$ or $>24 \mathrm{~mm}$, a modified SRK II formula is applied. ${ }^{y}$ In the former condition +1 is added to the $A$ constant, while in the latter condition -1 , or -2 is added to $A$.

In the triple procedure both the SRK and the SRK II linear regression formulae may be used after some necessary changes: $\mathrm{L}$ is the preoperative axial length of the operated eye; but $\mathrm{K}$ may be either (a) $106 \%$ the donor $\mathrm{K}$, or $(b)$ an arbitrary value of $45 \mathrm{D}$ if the donor $\mathrm{K}$ is not available.

It must be stressed, however, that the above statement is applicable only if (1) a $7.5 \mathrm{~mm}$ graft is placed in a $7 \mathrm{~mm}$ bed, and (2) the recipient bed is not heavily scarred. In this latter situation such eyes may benefit more by undergoing two separate surgical procedures: a penetrating keratoplasty and extracapsular cataract extraction followed later by a posterior chamber IOL after postoperative $\mathrm{K}$ values have stabilised. ${ }^{10}$

\section{References}

1 Sanders DR. Factors affecting accuracy of intraocular lens power calculations. In: Stark W, Terry AC, Maumenee AE, eds. Anterior segment surgery. Baltimore: Williams and Wilkins, 1987: 43-6.

2 Katz HR, Forster RK. Intraocular lens calculations in combined penetrating keratoplasty, cataract extraction and intraocular lens implantation. Ophthalmology 1985: 92: 1203-7. 
3 Charlton KH, Binder PS, Peril T. Visual prognosis in pseudophakic corneal transplants. Ophthalmic Surg 1981; 12: 411-9.

4 Troutman RC. Microsurgery of the anterior segment of the eye: the cornea, optics and surgery. St Louis, Mosby, 1977; 2: 107.

5 Casey TA. Corneal grafting and intraocular lenses. In: Rosen ES, Haining WM, Arnott EJ, eds. Intraocular lens implantation. St Louis: Mosby, 1984: 609.

6 Olson RJ, Mattingly TP, Waltman SR, Kaufman HE. Refractive variation and donor tissue size in aphakic keratoplasty. A prospective randomized study. Arch Ophthalmol 1979; 97: $1480-1$

7 Kozansky A, Cavanagh HD. The triple procedure: cataract extraction, intraocular lens insertion and corneal transplant. In: Stark W, Terry AC, Maumenee AE, eds. Anterior segment surgery. Baltimore: Williams and Wilkins, 1987:260)-6.

8 Binder PS. Intraocular lens powers used in the triple procedure. Effect on visual acuity and refractive errors. Ophthalmology 1985; 92: 1561-6.

9 Hope-Ross M, Mooney D. Intraocular lens power calculation. Eye 1988; 2: 367-9.

10 Musch DC, Meyer RF. Prospective evaluation of a regression determined formula for use in triple procedure surgery. Ophthalmology 1988; 95: 79-85.

Accepted for publication 3 March 1989. 